\title{
A DEFICIÊNCIA AUDITIVA NO CONTEXTO ESCOLAR: RECURSOS FACILITADORES DAAPRENDIZAGEM NO CONTEXTO PRESENCIAL E REMOTO
}

Ana Júlia Vieira Faria - graduanda em Psicologia - Uni-FACEF (Centro Universitário Municipal de Franca)

Marcelo Henrique Bastos - mestre em Educação - Centro Universitário Moura Lacerda anajuliav.faria@gmail.com

\begin{abstract}
RESUMO
Refletir a respeito da inclusão do aluno surdo e os métodos facilitadores de seu aprendizado no cenário presencial e remoto é o objetivo deste artigo. O processo educacional inclusivo do estudante com surdez é sublinhado por situações conflituosas e contestáveis. Entender a referida conjuntura é perceber que o indivíduo surdo tem sido negligenciado em seu processo de ensino - aprendizagem na rede regular de ensino. Comprometendo assim, seu desenvolvimento intelectual, social e pessoal. As controvérsias quanto ao método de ensino e as práticas pedagógicas ainda são desfavoráveis a esse grupo que possui cultura e identidade própria. Dessa forma o escopo pretendido é vislumbrar a surdez em um enfoque socioantropológico. Portanto, o arcabouço socioantropológico e Bakhtiniano permeiam as reflexões desse processo de análise da aprendizagem do aluno surdo.

Palavras-chave: Surdez, Ensino, Bakhtin
\end{abstract}

\section{INTRODUÇÃO}


O processo educacional do aluno surdo tem apresentado contradições e dilemas ao longo dos séculos. Na antiguidade o indivíduo surdo não era considerado ser humano por não conseguir desenvolver a fala. Os gregos afirmavam que o surdo seria incapaz de se desenvolver intelectualmente. Os romanos não viam capacidade do surdo em gerir seus próprios atos e dessa forma eram privados de seus direitos. (MOURA, 2000)

Esse cenário de desumanização não era diferente na visão dos religiosos. Segundo Moura (2000, p.16), "a igreja católica, até a idade média, acreditava que suas almas não poderiam ser consideradas imortais, porque eles não podiam falar os sacramentos". Esse olhar clínico, terapêutico e deficitário trouxe um processo de exclusão e negligência ao indivíduo surdo (QUADROS, 1997, PERLIN, 1998, SKLIAR, 1999).

Esse momento pandêmico trouxe uma nova conjuntura para o processo de ensino-aprendizagem e esse processo tem apresentado um grande dilema, isto é, como atender de forma eficaz o aluno surdo no contexto do ensino presencial e remoto. Muitos estudos já realizados comprovam que a exclusão do surdo no interior da escola é inconteste (SKLIAR, 2001, LACERDA, 2000). E com a necessidade de estudos remotos a situação se agravou, posto que, a interação que já era ineficaz, torna-se um grande desafio pela falta de preparo do educador. Corrobora a esse respeito Santos (2021, p. 5) quando afirma que:

A educação no atual contexto vem passando por momentos de grandes desafios e indecisões. O século XXI se destacou pelo avanço das tecnologias que hoje estão cada dia mais presentes nas escolas e por isso há necessidade de uma formação docente adequada.

Diante de referido pensamento é possível entender que além do desconhecimento da Libras pelo professor, há também o desconforto com o uso da tecnologia, ferramentas estas, essenciais para a construção do diálogo. Corrobora Zavala (2013, p.153), quando declara que, "Dialogar com a cultura alheia significa abrir 
perguntas ao outro, e ao mesmo tempo buscar no outro, respostas para as suas interpelações, descobrindo, assim, novas possibilidades de sentido". Não há aprendizado sem sentido. E esse sentido é o que a escola não tem conseguido concatenar no surdo.

O objetivo do presente artigo é investigar os recursos facilitadores utilizados para a aprendizagem de deficientes auditivos no contexto presencial e remoto. Da mesma forma, entender o processo de aprendizagem desta população.

Para atingir tal objetivo, foi utilizada como metodologia a revisão bibliográfica. Com isso, optou-se por fazer uma busca nos estudos publicados sobre o tema e sintetizá-los no presente artigo.

\section{METODOLOGIA}

Como metodologia para o presente artigo, optou-se pela revisão bibliográfica. Esta se caracteriza, de acordo com Conforto, Amaral e Silva (2011, p. 1), como "um método científico para busca e análise de artigos de uma determinada área da ciência".

Para selecionar os artigos e estudos da temática proposta, foram realizadas pesquisas nas áreas de educação e psicologia da aprendizagem, levando em conta principalmente temáticas relacionadas à inclusão de deficientes auditivos.

O propósito desta pesquisa foi investigar e descrever os recursos utilizados para a aprendizagem de deficientes auditivos, tanto no contexto presencial, quanto no remoto. Para coletar tais dados, os autores do presente artigo recorreram à bibliografia, utilizando então estudos publicados sobre a temática escolhida.

Após selecionar os estudos, realizou-se a correlação dos dados que possibilitou a identificação dos recursos facilitadores utilizados para a aprendizagem de deficientes auditivos. Para a elaboração do presente artigo, foram utilizados onze estudos que tratam as seguintes temáticas: Língua Brasileira de Sinais, surdez, identidade da pessoa surda, educação de surdos, acessibilidade de surdos em sala de aula e durante o período de ensino remoto. 


\section{RESULTADOS E DISCUSSÕES}

Diante dos resultados obtidos pela revisão bibliográfica é perceptível que a educação de surdos ainda não se afastou do olhar clínico e deficitário. As adaptações às necessidades desse grupo continuam circunscritas a métodos oralistas que não garantem o real aprendizado desse grupo. Também é patente que a falta do conhecimento e domínio da língua de sinais pelo professor traz barreiras e consequências limitantes ao desenvolvimento da aprendizagem do indivíduo surdo.

Dessa forma a incongruência pedagógica tira a possibilidade de uma maior desenvoltura cognitiva por parte desse grupo minoritário. A esse respeito, Shimazaki, Menegassi e Fellin, (2018, p. 4) atesta que,

\footnotetext{
Sem conhecimento e domínio da língua de sinais, práticas pedagógicas descontextualizadas da realidade dos surdos se perpetuam, a repercutir negativamente na sua formação e identidade linguística, por conseguinte, a retratar uma aquisição do português escrito de maneira fragmentada.
}

A língua de sinais é um fator crucial para que haja o desenvolvimento cognitivo, social e cultural do aluno surdo, ou seja, se reconhecerem como participantes da sociedade. Como relata Ferreira (2015, p. 22090) "Através da LIBRAS o surdo é capaz de compreender o mundo em que vive, dar significados às palavras, comunicar-se, expor seus sentimentos, desejos, exercer seu papel em uma sociedade.

No que se refere à questão dos recursos facilitadores ao ensino remoto, o processo de interação, não se tornou mais plácido. A interação virtual acabou se manifestando como um "novo" complicador. Notou-se que as ferramentas utilizadas não contemplavam a participação e o envolvimento mais efetivo do aluno surdo. Em um contexto geral as ferramentas mais utilizadas foram: vídeo chamadas, plataformas digitais, youtube, celulares e whatsapp.

Referidos métodos de trabalho docente não contribuíram para um maior processo de interação do surdo. Pelo contrário, percebeu-se um maior afastamento relacional, situação esta agravada pela falta de experiência do professor em lidar com a 
tecnologia. Além da questão financeira, posto que, nem todos os alunos tinham as ferramentas e o acesso necessário para uma participação mais efetiva .

Santos e Barbosa (2021, p.12) colocam que:

De fato, com a pandemia, o trabalho home office ganhou força, e logo depois as videochamadas. E isso trouxe alguns outros desafios para alunos surdos, visto que a dificuldade que eles tinham já era grande em aulas presenciais. Foi observado que aulas remotas trouxeram problemas diferentes, como por exemplo, quando o professor fala e a voz chega mais baixa do que o esperado, ou quando o professor explica algum conteúdo e por falhas da conexão de internet o aluno surdo não compreende ou até mesmo quando há instabilidade das plataformas das aulas. Os professores passaram a ter um vínculo menor com os alunos, pois não os conhecem presencialmente, todos esses fatores fazem com que os alunos sejam prejudicados em seu desempenho escolar. Além disso, ainda existem outros fatores que também podem prejudicar o aluno com surdez, como: o professor que desliga a câmera ou algum aluno que fala sem ao menos aparecer na câmera, fazendo com que o estudante perca o contato visual dos lábios do professor e aluno; quando é compartilhado slides impedindo o estudante de visualizar o professor explicando o conteúdo e a sua fala pode chegar distorcida.

Portanto, o que se observou com o pensamento de (SANTOS e BARBOSA 2021) e os trabalhos pesquisados a situação do aluno surdo ainda se mantém distante do que seria ideal para este grupo linguístico.

\section{CONSIDERAÇÕES FINAIS}

Foi possível entender o processo de aprendizagem da pessoa com deficiência auditiva e com isso, conclui-se que para o ensino desta população é imprescindível o ensino e o uso da Língua Brasileira de Sinais por parte dos educadores. A LIBRAS se configura então como um dos principais recursos facilitadores da aprendizagem.

Ademais, o objetivo de investigar os recursos que facilitam o ensino de surdos no contexto remoto foi atingido. Percebeu-se que no ensino online, as ferramentas utilizadas não favoreceram a população estudada e dificultaram ainda mais a aprendizagem dos surdos. 


\section{REFERÊNCIAS}

FERREIRA, L.B.J. Língua Brasileira de Sinais - LIBRAS, Língua Natural do Sujeito Surdo. (2015). XII Congresso Nacional de Educação - PUCPR Formação de professores, complexidade e trabalho docente III Seminário Internacional de Representações Sociais, Subjetividade e Educação - SIRSSE IV Seminário Internacional sobre Profissionalização Docente (SIPD/CÁTEDRA UNESCO) IX Encontro Nacional sobre Atendimento Escolar Hospitalar - ENAEH Curitiba, 26 a 29 de outubro de 2015 Disponível em https://educere.bruc.com.br/arquivo/ pdf2015/18948 8134.pdf. Acesso em 01 out. 2021

LACERDA, C.B.F. o Intérprete de Língua de Sinais no Contexto de uma Sala de Aula de Alunos Ouvintes: Problematizando a Questão. In: LACERDA, C.B.F; GÓES, M.C.R.(Org), Surdez: Processos Educativos e Subjetividade. São Paulo: Editora Lovise, 2000. p. 51-82

MOURA. M. C. de. O Surdo: Caminhos para uma Nova Identidade. Rio de Janeiro: Revinter, Ltda, 2000. 151p.

PERLIN. G.T.T. História de vida surda: identidades em questão. Rio Grande do Sul: UFRS, 1998. 93 f. Dissertação (Mestrado em Educação)-Universidade Federal do Rio Grande do Sul.

QUADROS, R.M. Educação de Surdos: a aquisição da linguagem. Porto Alegre: Artes Médicas, 1997.

SAntos, G G. F; BARbosA, T. S. A Acessibilidade de Alunos com Surdez no Ensino Superior, Durante a Pandemia da COVID-19. GOIÂNIA/GO: PUC de GO 19 p. 2021 (TCC) - Pontifícia Universidade Católica de Goías - Fonoaudiologia. 
SANTOS, R. S. dos. Os desafios frente ao atendimento educacional especializado remoto para alunos com surdez em tempo de pandemia no centro Raimundo Nonato Dias Rodrigues. 2021. 12f. Artigo Acadêmico (Pós-Graduação em Informática na Educação) - Instituto Federal do Amapá, Macapá, AP, 2021.

SHIMAZAKI, Elsa Midori; MENEGASSI, Renilson José; FELLINI, Dinéia Ghizzo Neto.Atendimento ensino remoto para alunos surdos em tempos de pandemia. Práxis Educativa, Ponta Grossa, v. 15, p. 01-17, 2020. Disponível em:

https://revistas.apps.uepg.br/index.php/praxiseducativa/article/view/15476/2092092134 32.Acesso em: 01 out. 2021

SKLIAR, C.A. Invenção e a exclusão da alteridade deficiente" a partir dos significados da normalidade. Educação \& Realidade: das diferenças, 1999, v. 24, nº. 2, p.15-32.

SKLIAR, C. Um olhar sobre o nosso olhar acerca da surdez e as diferenças. In: SKLIAR. C. (Org.), A surdez: um olhar sobre as diferenças. Porto Alegre2 $2^{\mathrm{a}}$ ed. Porto Alegre: Mediação,2001. p. 07-32.

ZAVALA, I. O que estava presente desde a origem. In: BRAIT, B. (org.). Bakhtin: Dialogismo e polifonia.São Paulo: Contexto, 2013 p. 151 - 166. 